\title{
Temporal parameters of speech production in bilingual speakers with apraxic or phonemic paraphasic errors
}

\author{
Karin Theron ${ }^{1}$, Anita van der Merwe ${ }^{1}$, Donald A. Robin ${ }^{1,2} \&$ Emily Groenewald ${ }^{1}$ \\ ${ }^{1}$ Department of Communication Pathology, University of Pretoria, \\ Pretoria, 0002, South Africa \\ and \\ ${ }^{2}$ Department of Otolaryngology-Head and Neck Surgery \\ University of Texas Health Science Center, San Antonio \\ Mail Code 7777, 7703 Floyd Curl Drive \\ San Antonio, TX 78229-3900
}

Send correspondence to:

Anita van der Merwe

Department of Communication Pathology, University of Pretoria,

Pretoria, 0002, South Africa.

E-mail: anita.vandermerwe@up.ac.za

Phone: 2712-420 5762

Fax: $2712-4203517$ 


\begin{abstract}
Background: The Four-Level Framework of speech production (Van der Merwe, 1997) suggests that language of production of a bilingual speaker can be viewed as a contextual factor increasing the complexity of speech production. A comparison of first versus second language speech production in individuals with apraxia of speech or phonemic paraphasic speech errors may clarify the difference in the underlying disorders in these two populations.

Aims: This study examined the effect of first versus second language (L1 versus L2) speech production on specific temporal parameters of speech in bilingual normal speakers and bilingual speakers with either apraxic or phonemic paraphasic speech errors. The purpose was to determine if second language speech production will differentiate between normal speakers and speakers with speech level neurogenic disorders and between speakers with phonological planning or speech motor planning and programming disorders.

Methods and Procedures: Three persons with apraxia of speech (AOS), three with phonemic paraphasias (PP) and five normal speaking participants were included in the study. Participants were required to read phonemically similar L1 and L2 CVC words in a two word carrier phrase, five times each, at a normal and fast speaking rate. Acoustic analysis of on-target productions included vowel duration, utterance duration, utterance onset duration, and voice onset time. Data processing involved a descriptive approach using a measure of central tendency, namely, the mean. Intraparticipant comparisons were made across contexts (L1, L2, fast speaking rate and normal speaking rate).
\end{abstract}

Outcomes and results: Five participants with AOS and PP seemed to be influenced by speaking in L2 to a greater extent than the normal speakers and one participant with 
PP, in that they more frequently experienced difficulty with durational adjustments (decreasing duration in the fast speaking rate) in L2 than in L1. Furthermore, the participants with AOS or PP also exhibited a greater extent of durational adjustment in L1 than in L2.

Conclusions: The results of this study suggest that L2 speech production is more challenging than speech production in L1 for participants with either AOS or PP. The current study could not differentiate between all speakers with a disorder in phonological planning and speakers with a motor planning and programming disorder. Individual patterns appear to exist in speakers with PP. Increased processing demands seem to impact on the phonological planning and the speech motor planning and programming levels of speech production. 
Advances in recent years have led to a better understanding of the nature of neurogenic communication disorders. However, the underlying pathogenesis in the different neurogenic communication disorders remains unclear. The differentiation between apraxia of speech (AOS) and phonological paraphasias (PP) demonstrated by persons with aphasia has attracted much attention (Haley, Ohde, \& Wertz, 2001; Kent \& McNeil, 1987; McNeil, Weismer, Adams, Mulligan, 1990; Seddoh, Robin, Sim, Hageman, Moon, \& Folkins, 1996). Apraxia of speech (AOS) represents a motor planning and programming disorder while deficits in phonological planning underlie PP speech errors (McNeil, Robin \& Schmidt, 1997; McNeil, Doyle \& Wambaugh, 2000; McNeil, Pratt \& Fossett, 2004; Seddoh et al., 1996). However, some studies of speakers with PP also indicate motor level disorders and a sharing of features with AOS (Kent \& McNeil, 1987; McNeil, Weismer, et al., 1990; McNeil, et al., 1997; McNeil, et al., 2000). One way to clarify this issue is to study sound production deficits in people who are bilingual and demonstrate either AOS or PP. To this end the purpose of this study was to determine if first language (L1) versus second language (L2) speech production at typical and increased speech rates differentiate between normal speakers and speakers with sound level neurogenic disorders and between those with AOS or PP. The participants had to read three-word sentences in which the words were no longer than three phoneme structures, minimizing the load on phonological planning. The focus of the study was on temporal parameters in L2 speech production.

Current models of speech production enhance our understanding of normal and pathological speech and language processing and may therefore be instrumental in characterising the nature of neurogenic communication disorders (e.g., Levelt, 
1989; Kelso \& Tuller, 1981; Rogers \& Storkel, 1999; Van der Merwe, 1997). The Four-Level Framework (FLF) of speech sensorimotor control (Van der Merwe, 1997) differentiates between levels of processing and also highlights the influence of contextual factors on speech production and on the presenting features of neurogenic speech disorders. Examples of contextual factors include volitional as opposed to automatized speech utterances, familiar as opposed to novel utterances, the syllable structure, motor complexity and length of the utterance and speech rate (Van der Merwe, 1997). Speech production in a second language, that is less familiar to the speaker, is handled by the FLF as one influential contextual factor (Van der Merwe, 1997). An increase in contextual demand during speech production may challenge a weakness in the system, magnify the salient features of the disorder and elucidate the core nature of that disorder.

The FLF (Van der Merwe, 1997, In press) proposes a differentiation between linguistic-symbolic planning of the utterance, motor planning, motor programming and motor execution. Within this theoretical framework, PP in the speech of aphasic speakers is the result of a breakdown in phonological planning during the linguisticsymbolic planning phase, while AOS is a motor planning disorder which might also impact on motor programming of speech movements (Van der Merwe, In press). Typical signs of a breakdown in phonological planning would include errors in the selection and sequencing of phonemes resulting in substitution and trans-positioning of phonemes. A breakdown in speech motor planning would include an inability to recall the core motor plans of phonemes, identify and sequence the motor goals in these plans, plan interarticulatory synchronization, plan long sequences of motor plans, adapt motor plans to the phonetic environment and perform internal predictive control (Van der Merwe, 1997; Van der Merwe, 2007). Signs of such a disorder may 
be the inability or difficulty to produce certain sounds, sound distortions, slowed rate and lengthened intersegment and segmental duration especially in multisyllabic words and words in sentences (McNeil, et al., 1997; McNeil et al., 2004, Van der Merwe, Uys, Loots \& Grimbeek, 1987; Van der Merwe, 1997). Differentiation between the sound level errors of AOS and PP is complicated by shared features like sound substitutions, trial-and-error searching, and variability of errors (Kent \& McNeil, 1987; McNeil, Weismer, et al., 1990; McNeil, et al., 1997; McNeil, et al., 2000; McNeil, et al., 2004). According to McNeil et al. (2004) sound distortions, prolonged segment durations and prolonged intersegment durations are characteristic of AOS, but are not seen in PP and may therefore serve as differential diagnostic signs. McNeil et al. (2004) also state that increased contextual demand may impact on both disorders.

Regarding the influence of contextual factors on speech production, Van der Merwe (1997:6) proposed that these factors "affect the dynamics of motor control by exerting an influence on the mode of coalition of neural structures involved during a particular phase and on the skill required from the planning, programming and execution mechanisms". Although most of the processing stages involved in normal speech production are generally viewed as occurring in a fairly automatized fashion (Bock, 1982; Kent, 1990; Levelt, 1989), controlled processing is likely to be employed in more challenging situations (Kent, 1990; McNeil, Odell \& Tseng, 1991). The context of speech production can influence processing demands (Kent, 1990; Levelt, 1989; McNeil et al., 1991; Van der Merwe, 2007).

Studies investigating bilingual speech production in normal speakers, have focused on aspects such as voice onset time in the two languages (Caramazza, YeniKomshian, Zurif \& Carbone, 1973, Lisker \& Abramson, 1964), the amount of lip 
rounding for rounded vowels in Swedish and English (Lubker and Gay, 1981) and the neural substrates of bilingual language processing using positron emission tomography during repetition tasks in mono- and bilinguals (Klein, Zatorre, Milner, Meyer \& Evans, 1995). All these studies point towards differential production characteristics in second as opposed to first language speech production. Klein et al. (1995) found that the left putamen was activated during second language repetition tasks, but not during repetition tasks in the first language. From this observation they hypothesized that "activation of the left putamen is a function of the increased articulatory demands imposed by speaking a language learned later in life" (Klein et al., 1995:31). Speech production in a second language acquired later in life than the first language, also referred to as late bilingualism (Paradis, 1995), can influence the speech production process. Speech production in L2 is presumably a less familiar context of production and therefore not as automatized as in L1, increasing processing demands (Van der Merwe, 1997; In press; Van der Merwe \& Tesner, 2000).

Communication in L2 is hypothesized to increase the processing demands for two reasons. First, L2 might contain speech sounds that are not part of the speaker's L1 repertoire. Articulation of these sounds may therefore be motorically more complex due to the fact that the motor plans and programs for these sounds have not been as firmly established and as automatized as those of L1 sounds. Even the . adaptation of shared L1-L2 speech sounds to the phonetic environment (Van der Merwe, 1997) will not be as automatized in L2 as in L1, since the combination of phonemes may be different (Van der Merwe \& Tesner, 2000). Second, message formulation in L2 likely requires more conscious processing, since the vocabulary and grammatical aspects of L2 are not as familiar as those of L1 to the bilingual speaker. More conscious processing is thus required for accurate selection of words, 
formulation of grammatically correct sentences, and phonological planning of words. Phonological planning entails the selection and sequencing of phonemes (Levelt, 1989; Van der Merwe, 1997). During this stage of phonological encoding an abstract representation of the target utterance is formed by accessing lexical information about an item's internal composition (Levelt, 1989). Both linguistic and motor processing would therefore necessitate more conscious processing in the bilingual normal speaker (Van der Merwe \& Tesner, 2000). More conscious processing requires allocation of more attentional resources (Clark \& Robin, 1998; Levelt, 1989; Kent, 1990; Kent \& McNeil, 1987; McNeil et al., 1991; Whiteside \& Varley, 1998). However, the age at which a speaker acquires L2 and the frequency of use will probably influence automaticity of speech in L2.

Bilingual aphasia has been extensively studied (Centeno, 2005; Gil \& Goral, 2004; Kiran \& Edmonds, 2004; Kohnert, 2004; Paradis, 1995), but limited research has been done on speech production in bilingual speakers with AOS. One study, Van der Merwe and Tesner (2000), was the first on bilingual AOS and examined the nature and severity of speech errors in L1 and L2 in a bilingual speaker with AOS as judged perceptually. These researchers found that similar types of speech errors, for example, voicing errors, consonant substitutions, consonant distortions and vowel errors occurred in L1 and L2. However, a greater number of errors occurred in L2. They proposed that the participant experienced speech production in L2 as more demanding than in L1 and concluded that speech production in L2 presumably requires more conscious control, which, in turn, affects the motor dynamics of speech production.

The present study represents an examination of the effects of bilingualism on specific temporal parameters of speech in bilingual speakers with AOS or PP and 
normal speakers with no known brain pathology. The results reported here are part of a larger study by Theron (2003). To further increase the processing demands in both languages, a faster than normal speaking rate was also employed. Increasing speech rate place higher demands on the speech production system and consequently on motor control (Kent \& McNeil, 1987; McNeil, Liss, Tseng \& Kent, 1990, Van der Merwe, 1997). Phonetic and linguistic influences and changes in speech rate impact on segmental duration and may also influence temporal control of interarticulatory synchronization (e.g. voice onset time-VOT) (Kent \& Read, 2002). Speech rate may be reduced as compensatory strategy to adapt to or decrease the demands of the context in which speech has to be produced (Van der Merwe, et al., 1987; Van der Merwe, 1997). In this study the impact of L2 speech production and increased speech rate on vowel duration, total utterance duration, utterance onset duration and VOT of target words were determined. Target words starting with both voiced and voiceless plosives were included as the demands of interarticulatory control may differ. Results comparing mean VOT between normal speakers and persons with AOS have been found to differ for words beginning with either a voiced or voiceless plosive (Seddoh, et al., 1996). The current study focused on temporal control, though it is acknowledged that bilingualism (or multilingualism) may also impact on spatial dimensions due to changes in coarticulatory demands in a second language. A perceptual analysis and comparison of phonetic and phonemic integrity in bilingual speakers with neurogenic sound level errors may also reveal much about the effect of increased processing demands (contextual loading) and thereby about the underlying nature of these disorders. Due to the exploratory nature of the study and the need to include normal speakers, the current study focused on the temporal dimension of 
speech since a reduction in speech rate appears to be a natural compensatory strategy in circumstances of contextual loading (Van der Merwe, 1997; In press).

In the current study it was predicted that speech production in L2 would impact on temporal parameters in the speech of normal speakers, but that they would adapt to the more demanding speaking contexts (Ostry \& Munhall, 1985; Smith, 1992; Strand \& McNeil, 1996). It was also predicted that participants with AOS would experience difficulty making durational adjustments (decreasing duration in the fast rate) in both L1 and L2, but more so in L2. Due to the underlying disorder in speech motor planning and programming, durational adjustments would be more demanding in the less familiar context of L2 speech production, particularly during increased speech rate. It was further predicted that speakers with PP would also react to the increased processing demands but that like normal speakers they would be better able to accomplish durational adjustments than those with AOS. L2 speech production should have less of an effect on speakers with PP than on speakers with AOS.

A study of the influence of speech production in L1 and L2 in circumstances of increased processing demands renders novel opportunities to infer more about the nature of the speech production process in bilingual normal speakers. The inclusion of speakers with disorders in different phases of the speech production process may further enhance our understanding of the effect of a disorder and the nature of such breakdowns.

\section{METHOD}

\section{Participants}

Two experimental groups participated in the study. They comprised three participants with AOS (two females and one male) and three participants with predominant PP 
(two males and one female). The ages of the participants with AOS and those with PP ranged from 43 to $59($ mean $=57)$ years, and 64 to $85($ mean= 74$)$ years, respectively.

The participants in the AOS group (AOS1-AOS3) had a single lefthemisphere lesion as determined by neuroradiologic reports and were diagnosed with AOS by means of perceptual judgement by two speech-language pathologists with over ten years of clinical experience in the assessment and diagnosis of neurogenic speech and language disorders. Speech characteristics included the presence of effortful trial-and-error groping of the articulators (Kent \& Rosenbek, 1983), dysprosody (Kent \& Rosenbek, 1983; McNeil et al., 1997) difficulty with initiation of speech movements (Kent \& Rosenbek, 1983) and errors of speech sound distortion (McNeil et al., 1997), including distorted perseverative, anticipatory and exchange phoneme or phoneme cluster errors (McNeil et al., 1997). Sound distortion was considered to be present if production of some vowels or consonants did not perceptually reach the critical acoustic configuration due to spatial misplacement or temporal mistiming (e.g. VOT errors) and was judged perceptually off-target by narrow phonetic transcription. Near normal scores on the Western Aphasia Battery (WAB) (Kertesz, 1982) ascertained that participants had minimal accompanying aphasia. The participants with AOS displayed no weakness or incoordination of the speech musculature when used for reflexive or automatic acts, thus excluding the presence of dysarthria.

The participants included in the PP (PP1-PP3) group exhibited undistorted sound substitutions, including perseverative, anticipatory and phoneme exchange or phone cluster errors and near normal speech rate when producing on-target phrases and sentences. The Western Aphasia Battery (WAB) (Kertesz, 1982) was administered to each participant to determine the type and degree of aphasia. Two 
persons presented with conduction aphasia and one with anomic aphasia. Participants were excluded from this experimental group if they exhibited oral weakness or incoordination.

In addition to the two experimental groups, five non-brain injured participants served as a comparison group (N1-N5). This group consisted of three females aged 43, 59 and 87 respectively and two males aged 63 and 74. The ages of the comparison group ranged from 43 to 87 years to serve as controls for the speakers with AOS or PP whose ages ranged from 47 to 87 years. These participants were without any history of speech, language, cognitive or neurological impairment as determined during a case history interview. They exhibited normal speech and language skills as judged perceptually by the two speech-language pathologists mentioned previously. Perceptually the speech of these participants had to be error-free and fluent with normal grammatical organization.

Participants in all three groups were bilingual Afrikaans and English speakers, who had attended Afrikaans primary and secondary schools. English had been introduced in school as L2 at the age of eight to nine years and was not spoken as a home language during any time of their upbringing or school career. Their use of English as second language was limited to formal classes in school. The level of bilingualism between participants was matched as closely as possible. Afrikaans was chosen as L1 and English as L2, since the majority of clients receiving speechlanguage services in the area where the study was performed were Afrikaans L1 speakers. Only L1 was treated in therapy. Furthermore, all participants exhibited adequate reading skills to enable them to read the presented test stimuli aloud. All participants gave informed consent to participate in the study and for the results to be 
published. The biographical data of the experimental participants and WAB (Kertesz, 1982) test results are displayed in Table 1.

(Table 1 about here)

Speech stimuli

Afrikaans and English target words that were similar with regard to syllable structure (consonant-vowel-consonant) and phonetic features (as determined by narrow phonetic transcription), were used as speech stimuli (Table 2). Each L1 word had a counterpart in L2 that was phonetically identical, except for qualitative differences as explained below. Although the semantic meaning of the sets of target words differed between languages in some instances, all words were nouns (in both languages) to counteract the possible influence of word class. The study of different languages will invariably encounter this type of problem and it was more important that the words in each language were meaningful as opposed to nonsensical. Lexical frequency in the two languages were not compared, but all stimuli were common nouns. The important factor in this study was to control the phonetic-motoric complexity of the target words.

(Table 2 about here)

Although the target words that were selected were phonetically similar in English and Afrikaans, they were not identical owing to, for example, aspiration of English plosives and subtle vowel differences. Despite qualitative differences between the vowels in L1 and L2, the place of articulation of the two vowels in each language was similar. Qualitative differences existed, for example, between the "u"-sounds in English and Afrikaans words. For example, the word "fuss" in English is transcribed as /f $\Lambda \mathrm{s} /$, whereas "vas" in Afrikaans is transcribed as /fas/. The selected vowels were, however, the counterpart of each other in each language. 
Five of the selected target words each began with a voiceless plosive (VLP) and five with a voiced plosive (VP). All target words consisted of the structure consonant-vowel-consonant (CVC) and were embedded in a carrier phrase (which had the same meaning), namely, "It's a __" (/itsə ___ in English and "Dis 'n __ " (/dəsə _ _ / ) in Afrikaans. Target words beginning with plosives were selected since they allow for measurement of temporal variables such as VOT and utterance onset duration.

\section{Data collection}

The participants were instructed to read each target utterance from a card presented by the researcher. For data recording a unidirectional FOSTEX M-2 microphone was placed about fifteen centimeters from the subject's mouth and the signal was recorded on a TDK Brilliant B Type I Cassette, using a Marantz Stereo Cassette Recorder CP430. Each of the ten stimuli was presented five times in random order. The Afrikaans utterances were recorded first and after a short rest period, the English utterances.

The data collection procedure for each language involved two different tasks, namely, reading utterances at a normal speaking rate (NR) and at a fast speaking rate (FR). The NR utterances were recorded first and thereafter utterances produced at a FR. During the normal rate condition, the participants were instructed to read each utterance at a normal, comfortable speaking rate. During the fast rate condition the participants were instructed to read each utterance as fast as possible without compromising speech intelligibility. Since not all participants were able to increase speaking rate to the same extent relative measures were used during data analysis. Accordingly, the speed in the fast rate was expressed as a percentage of the speed in the normal rate for each individual separately. Each speaking rate was demonstrated 
by the researcher before recording of the data for the specific rate condition commenced. The first author modelled an increased rate two to three times to each participant individually. Speaker specific analysis of data counteracted any possible influence of a variation in the model. Participants were allowed to practise an increase in rate before data recording commenced. The practice item was not included in the test stimuli. The order of L1 and L2 word sets and the order of the rate condition were not randomised across subjects to counteract the potential effect of fatigue as variable. Participants had to attempt production until they succeeded in producing the target word correctly.

\section{Data analysis}

To determine the effect of speech production in L1 and L2, durational measurements were made for four dependent variables: (1) vowel duration (VD), (2) total utterance duration of the target word (UD), (3) utterance onset duration (UOD), and (4) voice onset time (VOT). Each dependent variable and specific rules for measurement are described below. To illustrate the specific measurement points for utterances beginning with a voiceless plosive, Figure 1 is provided.

The recorded signal was acoustically analyzed using a software program, CSL50 (Version 5.X) (Kay Elemetric Corporation, 1994), in conjunction with the Computerized Speech Laboratory (CSL) 4300B analyzer. Only on-target utterances as determined by narrow phonetic transcription were used for analysis. The analysis program provided a simultaneous display of the acoustic waveform and spectrogram of the speech signal, which allowed for comparison and consequently more reliable measurement. Acoustic measurements were performed using a dual display of sound wave energy and a wideband spectrogram (bandwidth $=375 \mathrm{~Hz}$, frequency range 0$8000 \mathrm{~Hz}$ ). The signal was sampled at a rate of $22 \mathrm{kHz}$. From the spectrogram, 
durational measurements were made by placing adjustable time cursors at the beginning and end points of each defined area. The five trials of each utterance (when five on-target productions were available) were analyzed. The only off-target tokens that could not be used for analysis were one each for N2 and N4 in the L1FR condition, one token for AOS1 in L1NR, one in L2FR and one in L1FR and one for AOS2 in L1NR.

(Figure 1 about here)

\section{Vowel duration}

Vowel onset was determined by the beginning of periodicity on the waveform and the spectrographic display and/or the beginning of significant formant energy on the spectrogram. The end of the vowel was characterized by the end of formants and periodic energy.

\section{Utterance duration}

In target words beginning with a voiceless plosive, UD was measured from the beginning of the energy burst (indicating closure release) to the end of spectral energy. Although articulation for the initial plosive commences with lip closure before the release of oral constriction, it was not possible to detect the closure phase spectrographically. The reason for this was that in normal participants one could have assumed that the onset of lip closure occurred directly after the end of the carrier phrase, but this was not always the case for the experimental participants. Some of the experimental participants occasionally repeatedly attempted production of the target word, producing the first phoneme or phonemes several times before successful production of the complete target word. The energy burst related to production of the complete target word, was then taken as the position for placement of the first cursor. 
UD was measured from the energy burst of the initial plosive to the end of spectral energy of the target word. In instances of voicing lead or instances where participants maintained voicing throughout production of the carrier phrase and the target utterance, the energy burst indicating closure release was thus still taken as the start of UD.

\section{Utterance onset duration}

Utterance onset duration was measured from the end of the periodic acoustic energy for the last sound of the carrier phrase (//) to the energy burst indicating closure release for the initial plosive of the target word. In instances of voicing lead the final measurement point for UOD was still taken as the start of the energy burst and not the start of voicing.

\section{Voice onset time}

Voice onset time of word-initial plosives was measured in words beginning with a voiceless stop consonant. The VOT of words beginning with a voiced plosive could not be used for analysis since some speakers exhibited instances of voicing lead. The latter factor resulted in a negative VOT that was not compatible with the formula used for data analysis. VOT in utterances beginning with a voiceless plosive was measured from the start of the energy burst for the initial plosive to the start of vocalization determined by the first sign of periodicity. In utterances beginning with a voiceless plosive, voicing always followed the stop release (voicing lag) with all VOTs for voiceless plosives being positive.

\section{Data processing}

Data of the experimental participants were processed for each individual participant, whereas data for the normal speakers were processed for both individual participants (due to the small sample size) and for the normal speakers as a group. The data of the 
experimental participants was not grouped as individual performance differed too much. Grouping data of such a small number of participants might have led to one participant's data dominating the group data.

For each participant the mean duration (in milliseconds) of each temporal parameter (VD, UD, UOD and VOT) was calculated for each target word within each context (L1NR, L1FR, L2NR, L2FR) using the durational values of each participant's five repetitions of a specific utterance. These mean durational values for each target word were then used for further processing of the data.

Graphic representations of data were constructed using bar graphs (Figures 2 to 8). Tables were also compiled to summarize the findings and highlight main trends (Tables 3 and 5). Because of the subtle vowel differences between the English speech stimuli and their Afrikaans counterparts, direct comparison between the absolute durations and measurements obtained for L1 and L2 was not possible. Productions were thus compared across the two speaking rates (fast and normal rate), within each language. Furthermore, results of the experimental participants were compared to those of the normal group for each language and rate condition separately. Relative measures of duration were used.

To determine the extent to which a participant decreased or increased the duration of a specific temporal parameter in the FR compared to the NR, the duration in the FR was expressed as a percentage of the duration in the NR. The extent of durational adjustment (percentage value) was calculated for each language, temporal parameter and target word separately, using the formula $100 \times$ [1 minus (duration in the FR divided by the duration in the NR)]. When a value $>0$ was obtained, it indicated that the duration of the specific temporal parameter had been decreased in 
the FR condition. A value $<0$, on the other hand, indicated that the person had not successfully decreased duration in the FR and that the duration had, in fact, increased.

After calculating the percentage of durational adjustment for each temporal parameter for each utterance of each participant and for the normal group, an average percentage of the extent of durational adjustment in the FR compared to the NR was calculated for each of the two utterance groups (VP and VLP). The extent of durational adjustment for each utterance group was calculated by first adding the percentage values of durational adjustment of each utterance in a specific utterance group. Second, this value was divided by the number of utterances in the group. The former calculation yielded a percentage value depicting the extent of durational adjustment for each of the two utterance groups (either VP or VLP). The latter value was calculated for each temporal parameter for each participant and language separately, as well as for the normal speakers as a group. Bar graphs were then constructed to illustrate the extent of durational adjustment in the FR compared to the NR for each temporal parameter for each participant and the normal group for each utterance group. Figures 2 to 8 display the percentage values depicting the duration of each measured temporal parameter in the FR expressed as a percentage of its duration in the NR (extent of durational adjustment) for each participant and the normal group in $\mathrm{L} 1$ and L2 respectively.

\section{Reliability}

Inter-rater reliability was not done formally, but during the initial phase of analysis of each participant's data, the first and fourth authors analysed ten percent of that data by consensus. The fourth author has more extensive experience in this field than the first author and this procedure was followed to ensure reliability of measurements. 
Ten percent of the data was reanalysed by the first author to determine intra-rater reliability. The first ten percent of recorded utterances for each rate condition and language of each participant was used for reanalysis. A second spectrogram of each of these utterances was made and each temporal parameter was measured again by hand. If the difference between the original measure and the reliability measure was not more than 3 milliseconds (Seddoh et al., 1996), or if these two measures did not differ by more than two increments, the two measures were accepted as being in agreement. Intra-rater reliability was determined by dividing the total number of reanalysed utterances that were in agreement with the initial measurements by the total number of utterances that were reanalysed (Shriberg \& Kent, 1982). Point-to-point comparison revealed an intra-rater agreement of $89 \%$.

\section{RESULTS}

To determine if L2 led to greater difficulty with durational adjustments, a table was compiled (Table 3) indicating whether one of four scenarios occurred. First, it was indicated whether durational adjustment in the FR was successfully accomplished in L1 only (scenario A). Second, it was indicated whether the extent/percentage of durational adjustment in the NR compared to the FR in L1 was greater than in L2 (scenario B). The presence of either of these aforementioned scenarios would imply that it was more difficult to accomplish durational adjustments in L2 than in L1. Third, it was indicated whether durational adjustment in the FR was only successfully accomplished in L2 (scenario C) and fourth, it was indicated whether the extent/percentage of durational adjustment in the NR compared to the FR in L2 was greater than in L1 (scenario D). The presence of scenarios C and D would imply that it was presumably more difficult to accomplish durational adjustments in L1 than in 
L2. "Not applicable" (NA) is indicated in Table 3 if comments regarding the extent of durational adjustment in L1 compared to L2 could not be made due to the fact that the duration in the FR could not be decreased in either language. The latter would imply that increasing rate, thus decreasing duration in the FR, was too difficult a task for the participant in either language. The exact percentage values, depicting the extent of durational adjustment for each language, utterance group and participant, from which these tables were compiled, are displayed in Table 4.

Finally a table was compiled to summarize findings across utterance groups and dependent variables (Table 5). In this table the percentage of times scenarios A to D occurred is indicated, as well as the percentage of times across the seven observations (four dependent variables with either VP, VLP or both utterance groups) that a subject could not decrease duration in the FR in either language.

\section{Vowel duration}

The percentage of adjustment of vowel duration in L1 and L2 for each participant and the normal speakers as a group is displayed in Figures 2 (utterances beginning with a voiceless plosive-VLP) and 3 (utterances beginning with a voiced plosive-VP). A value $>0$ indicates that duration was decreased successfully in the fast rate, while a value $<0$ indicates that duration in the fast rate was longer than in the NR condition.

(Figures 2 and 3 about here)

Four of the five normal speakers were able to decrease duration in the FR successfully in both L1 and L2. Furthermore, the normal speakers as a group displayed only scenario D in that duration was decreased in the FR to a greater extent in L2 as opposed to L1 for both utterance groups (see Table 3). The actual percentage values are displayed in Table 4.

(Table 3 about here) 
(Table 4 about here)

It appears as if the L2 context led to the occurrence of scenario A (successful durational adjustment in L1 only) and scenario B (greater percentage of durational adjustment in L1 than in L2) in AOS2, AOS3, PP2 and PP3 regarding either the VP or VLP utterance groups or, in some instances, both utterance groups. As with the normal group, PP1 did not seem to have been affected by the L2 context in that this participant displayed only scenario D.

\section{Utterance duration}

The percentage of durational adjustment for utterance duration in L1 and L2 for each participant and the normal speakers as a group is displayed in Figures 4 (VLP utterance group) and 5 (VP utterance group). From these figures and the summarized findings in Table 3, it is evident that the normal group was always able to decrease duration in the FR and as with vowel duration, only displayed scenario D. (19.9\% in L2 and $17.1 \%$ in L1 for the VLP group and $19.9 \%$ in L2 and $19.1 \%$ in L1 for the VP group).

(Figures 4 and 5 about here)

From Figures 4 and 5, it is evident that five of the six experimental participants were able to decrease duration in the FR in both languages. For the VLP utterance group all the experimental participants displayed scenario B (achieving a greater percentage of durational adjustment in L1 compared to L2), whereas for the VP utterance group four of the six experimental participants displayed scenario B. AOS1 and PP3 performed similar to the normal group in that they achieved a greater percentage of durational adjustment in L2 as opposed to L1 for the VP utterance group. 


\section{Utterance onset duration}

The results depicted in Figures 6 and 7 and Tables 3 and 4, indicate that the normal group was successful in decreasing utterance onset duration in the FR in both languages for both utterance groups. Four of the five normal speakers displayed a greater percentage of durational adjustment in L1 compared to L2 for the VLP utterance group (29.6\% in L2 and $33.4 \%$ in L1, thus scenario B), whereas three of the five normal speakers displayed scenario B for the VP utterance group. The normal speakers as a group, as well as individual participants N1 and N4 displayed scenario D (a greater percentage of durational adjustment in L2 than in L1) for the VP utterance group.

(Figures 6 and 7 about here)

Participant AOS1 could not decrease utterance onset duration in the FR in either L1 or L2 for the VLP utterance group. Three of the six experimental participants (AOS2, PP2 and PP3) could decrease utterance onset duration in the FR in L1 only (scenario A) for the VLP utterance group and two of the six experimental participants (AOS3 and PP3) displayed scenario A for the VP utterance group.

Five of the six experimental participants (AOS2, AOS3 and all subjects with PP) obtained a greater percentage of durational adjustment in L1 than in L2 (scenario B) for the VLP utterance group, while four of the six experimental participants (AOS1, AOS3, PP2 and PP3) exhibited scenario B for the VP utterance group. AOS2 and PP1 exhibited scenario D (a greater percentage of durational adjustment in L2 than in L1) for the VP utterance group.

Voice onset time

From the results depicted in Figure 8 and Tables 3 and 4, it appears that VOT was generally reduced in both L1 and L2 by the normal speakers as a group and individual 
normal speakers, with the exception of $\mathrm{N} 2$ and $\mathrm{N} 3$ for L1. As a group the normal speakers displayed only scenario D.

(Figure 8 about here)

It is evident from Figure 8 that AOS1 was successful in decreasing VOT in the FR only in L2 (scenario C), whereas PP2 could decrease VOT in the FR only in L1 (scenario A). Five of the six experimental participants were able to decrease duration in the FR in L2, when being able to do so in L1. Regarding the extent of durational adjustment in the FR in L1 compared to L2, it is evident that only PP2 and PP3 exhibited a greater percentage of durational adjustment in the FR in L1 than in L2 (scenario B). Four of the six experimental participants (all speakers with AOS and PP1) performed similar to the normal group in displaying scenario D.

\section{General summary of results}

In Table 5 the percentage of instances across dependent variables and utterance groups in which scenarios A to D were displayed for each participant and the normal speakers are provided. From this table it is evident that the normal speakers (with the exception of $\mathrm{N} 2$ and $\mathrm{N} 3$ in L1) were generally able to decrease duration in the FR successfully. Furthermore, the normal speakers never exhibited scenario A (decrease of duration in L1 only). The normal speakers as a group also generally exhibited a greater percentage of durational adjustment in L2 (86\% of observations) than in L1 (14\% of observations) (scenario D).

Contrary to the results of the normal speakers, AOS1 (43\% of observations), PP2 (14\%) and PP3 (14\%) displayed instances where duration could not be decreased in both L1 and L2. It is further evident from this table that AOS2, AOS3, PP2 and PP3 displayed quite a few instances (ranging from 14 to $71 \%$ ) where duration in the 
FR could only be decreased in L1 (scenario A) and never instances where duration could only be decreased in L2 (scenario C). Furthermore, four of the six experimental participants (AOS2, AOS3, PP2 and PP3) more often exhibited scenario B (a greater percentage of durational adjustment in L1 than L2) (ranging from $71 \%$ to $86 \%$ of observations) than scenario D (a greater percentage of durational adjustment in L2 than L1) (ranging from $0 \%$ to $29 \%$ of observations).

(Table 5 about here)

In summary, the main findings of this study were that the normal speakers were generally able to adjust to the increased demands of increasing speaking rate and speech production in L2 and obtain the motor goal of shorter duration. Furthermore, contrary to all the speakers with AOS and two of the three speakers with PP, a greater extent of durational adjustment was generally achieved in L2 compared to L1. The speakers with AOS and those with PP attempted to decrease duration in the FR, but were not consistently successful in doing so. Thus, although these speakers achieved perceptually accurate speech production, the motor goal of decreasing duration was often not obtained. The latter finding was more prevalent in L2 than in L1. No specific pattern emerged for utterances beginning with either a voiced or voiceless plosive.

\section{DISCUSSION}

The results provided support for the prediction that L2 can be viewed as a context that increases the complexity of speech production for all speakers, but the study did not differentiate between speakers with AOS and all speakers with PP. The findings will be discussed with reference to the differentiation between AOS and PP, the ability to accomplish durational adjustments, the effect of L1 versus L2 on this ability and L2 as context for speech production. 


\section{The differentiation between AOS and PP}

The speech task in this study did not differentiate between AOS and all speakers with PP. One of the speakers with PP (PP1) reacted like the control speakers while two reacted like the participants with AOS. This result argues again the presence of motorbased problems in all persons with PP. It is possible that the level of bilingualism had an effect on the results. However, the inconsistency in the data appears to be a contraindication for such an explanation. The most acceptable explanation for the current results is that contextual loading in the form of less familiar utterances in conditions of increased rate, may impact on both the phonological planning level and the speech motor planning and programming levels. However, the impact may vary from one speaker to another and even from trial to trial in some speakers. The three participants with AOS reacted similarly in most instances and these results are consistent with a motor-based disorder in AOS.

Speech motor planning and programming happens in real time while an utterance is planned. The phonetic context in which sounds are to be produced change with each word and string of words and adaptation of spatial and temporal parameters has to take place (Van der Merwe, 1997). The task in the present study required this kind of controlled planning and programming (Van der Merwe, 2007) and it is therefore not surprising that the participants with AOS were influenced by this context. Independent or active phonological planning on the other hand was limited in the task. A translation from the orthographic representation of the words to an abstract linguistic sequence of phonemes was necessary. In spite of the nature of phonological planning required in this study, two of the participants with PP were influenced by this context. The reasons may be that phonological planning is taxed even in these 
circumstances or it may be that the entire context of producing a sentence in a second language place more demands on the system of a speaker with PP. The impact may depend on the severity of the phonological disorder. PP1 who reacted like the normal speakers had the highest aphasia quotient on the WAB and possibly the less severely compromised phonological planning system. Both groups had speech level errors and had to target error-free speech. This demand alone can therefore not account for the present results.

\section{The accomplishment of durational adjustments}

The normal speakers were generally successful in decreasing duration in the fast rate. Speakers with AOS or PP (except for PP1) attempted to increase speaking rate, as reflected by a reduction in duration of temporal parameters in the FR, but were not consistently successfull. Thus, although these speakers achieved perceptually accurate speech (only on-target utterances were analyzed), the motor goal of decreasing duration was often not attained. Previous studies have also reported difficulty with rate adjustments in persons with either AOS or conduction aphasia implying a motoric inflexibility in these speakers (Kent \& McNeil, 1987; McNeil, Liss, et al., 1990).

Motoric inflexibility as reflected in this study might be due to a number of reasons. One explanation might be related to the fact that processing resources are presumably shared amongst the different levels or processes of speech production and that these different levels or processes interact (Strand \& McNeil, 1996). In this regard, Kent and McNeil (1987) and Rosenbek (2001) have speculated that the speech production mechanism might have a limited number of ways to exhibit breakdown. In other words, a deficit at the level of linguistic-symbolic planning as in persons with PP might therefore also manifest in difficulty with temporal control in that the 
phonologic plans that are sent to the motor system may be delayed or somehow inefficient and thereby result in an overload on the speech motor planning and programming system. In persons with AOS, motoric inflexibility is to be expected due to the presumed motor planning and programming deficit in these persons.

Another reason for difficulty making durational adjustments might be related to increased demands imposed by an increase in speaking rate. As learning occurs, a motor act can be performed at a faster rate (Jaric, Corcos, Argarwal \& Gottlieb, 1993), implying that skill is needed for faster performance. Speaking at a faster than normal rate will presumably increase the processing demands on both a linguistic (Fossett, McNeil \& Pratt, 2001) and motor level (Kent \& McNeil, 1987; Van der Merwe, 1997, 2002). Operations involved in linguistic-symbolic planning, for example, phoneme selection and sequencing will thus need to occur more rapidly. On a motor level, operations involved in motor planning and programming, include, recall of motor plans or programs from working memory, activation of parameters of programs such as absolute timing and spatial representation of the intended movement, and ultimately sequential organization of movements with coarticulation packaged into a shorter than usual time frame thereby creating a large load on the motor control system (Van der Merwe, 2002).

Another explanation for the difficulties experienced by persons with AOS and those with PP when speaking rate adjustments are imposed, could be due to a compensatory strategy employed by these participants under any circumstances which increases processing demands. When having to increase speaking rate, persons with either AOS or PP might automatically slow down their speech rate (resulting in increased durations) and apply more conscious processing as a compensatory strategy to achieve perceptually accurate speech. A trade-off thus results between the 
achievement of the motor goal (increasing rate) and achievement of perceptually accurate speech.

The fact that some of the normal speakers in the present study also occasionally failed to decrease duration in the FR, is indicative of the fact that even the normal motor speech system exhibits periods of inconsistent behavior when processing demands are increased, although this is rather the exception than the rule. It could also have been that the normal speakers produced the carrier phrase at a faster than usual rate, but not the target utterance which was used for analysis.

The effect of speech production in L1 versus L2 on the accomplishment of durational adjustments

The results of the normal group do not indicate that these speakers were affected by the L2 context regarding the extent of durational adjustment. In fact, the normal group often obtained a greater extent of durational adjustment in L2 compared to L1 (86\% of observations in L2 as opposed to $14 \%$ of observations in L1). The normal speakers as a group only exhibited a greater extent of durational adjustment in L1 than in L2 for UOD of the VLP utterance group. The reason for the normal speakers attaining a greater extent of durational adjustment in L2 compared to L1, could be due to the fact that some speakers exert more conscious control whilst speaking in L2, since this is a less familiar context than L1. Conscious control whilst speaking in L2, might then lead to the accomplishment of greater durational adjustments in L2 compared to L1.

From the results of this study it is evident that the L2 context appears to have posed a greater demand on the speech production mechanisms of most of the participants with either AOS or PP. All the experimental participants, with the exception of AOS1 and PP1, exhibited a greater extent of durational adjustment 
regarding $\mathrm{VD}$, UD and $\mathrm{UOD}$ in the FR in L1 compared to L2 (scenario B) in at least one of the utterance groups. Participant PP1 did not exhibit a greater extent of durational adjustment in L1 compared to L2 for any utterance group, regarding both VD and VOT. This participant exhibited behavior similar to the normal group who only exhibited a greater extent of durational adjustment in L1 than in L2 for UOD of the VLP utterance group.

The influence of speech production in L2 was also evident in the experimental participants as reflected by the fact that an ability to decrease duration in the FR was often evident only in L1 (scenario A). In other words, a particular participant was able to successfully decrease duration in L1, but not in L2. This finding pertained to four of the six experimental participants, whereas none of the normal speakers exhibited this behavior.

The fact that most of the participants with either AOS or PP exhibited a greater extent of durational adjustment in the FR in L1 than in L2 (scenario B), implies that temporal control in L1 was more successfully and presumably more easily exerted by these participants under circumstances of increased processing demand. The same explanation holds true for the finding that most experimental participants were often successful in decreasing duration in L1 only.. The fact that L1 did not, however, consistently render a greater extent of durational adjustment than L2, in either the experimental participants or the normal group, indicates that performance is variable. The variability in performance regarding utterance groups and specific parameters is also true for the findings regarding the accomplishment of durational adjustments in L1 compared to L2. Consequently the L2 context did not unequivocally negatively influence temporal control of all parameters and all 
utterance groups. However, the fact that the experimental participants generally achieved a greater extent of durational adjustment in L1 and often experienced difficulty with durational adjustment in L2 only, strongly suggests that when rate has to be increased, L2 further increases the processing demands in speakers with compromised speech and language processing. It could be that the parameters examined in the current study were not sensitive enough to consistently display difficulties experienced in L2. To more clearly delineate the influence of L2 on motor control, an analysis of spatial parameters (e.g. coarticulation), together with temporal parameters of speech production, might be useful in highlighting the extent and nature of deficits in AOS and PP, as well as the occurrence of trade-offs during speech production in L1 and L2 respectively. A study of variability regarding durational adjustments in the different participants may also have revealed differences between the different groups of participants. By studying various aspects of speech motor control, differences between persons with a breakdown at different levels of the speech production process might be more readily identified.

\section{L2 as a context for speech production}

From the above discussion it is evident that L2 can be regarded as a context that increases the complexity of production for most persons with either AOS or PP in the present study. However, the normal speakers as a group did not seem to be affected by the increased demands imposed by speaking in L 2 in the same manner as persons with either AOS or PP. It can be hypothesized that in normal speakers, speaking in L2 should presumably not be problematic under ideal circumstances (producing simple phrases with words which are phonemically and phonetically similar in the two languages), since the normal speech motor system is flexible in adjusting to increased demands. 
The reason for L2 being viewed as a contextual factor can be related to the concept of automaticity. A task becomes "automatic" with practice (Magill, 2007; Schmidt, 1988). Once it becomes automatized, little conscious control needs to be exerted for execution thereof (Kent, 1990). Speech production in L2 is not produced with the same degree of automaticity as L1 due to the fact that it has not been "practiced" as often as L1. Consequently more conscious processing on a linguistic and motor level is required for its production. The level of automaticity that L2 reaches will depend on the level of bilingualism of a particular participant. If L2 was acquired early on in life a greater level of automaticity will presumably be reached. The level of bilingualism of the participants in the present investigation was controlled as far as possible. The fact that participants with AOS already have difficulty regarding the motor planning and programming of speech might result in these speakers being less successful with the operations involved in motor control when the processing demands are increased by a novel or less automatized utterance. Similarly, some persons with PP might find the operations involved in thís stage of speech production more difficult when the processing demands are increased. Regarding the motor planning of speech, recall and adaptation of motor plans for L2 might be less automatized and consequently L2 contributes to the complexity of the utterance. Similarly, selection and sequencing of phonemes in L2 might be less automatized and contribute to greater complexity of the utterance. The greater complexity of the utterance in turn leads to a need for greater resources. Persons with AOS or PP, in reaching the limits of their capacity, might thus not have sufficient resources for executing a more complex task. 
The finding that L2 influences the temporal parameters of speech production is consistent with the conclusions drawn by other researchers examining the effect of linguistic variables on speech production. These researchers concluded that increased processing demands at a "higher level" of the speech production process, influence "lower level" processes and consequently the motor output stage of speech production (Abbedutto, 1985; Maner, Smith \& Grayson, 2000; Strand \& McNeil, 1996). Maner et al. (2000) posed that the greater variability exhibited by the participants in their study during production of more complex sentences was indicative of the fact that patterns of activity caused by the neural networks that generate motor commands to the muscles, are less stable when processing demands are higher. Maner et al. (2000) further postulated that the decreased stability in the pattern generation circuitry could be related to speech production processes operating in parallel and interacting with cognitive, linguistic, and motor planning or programming.

Regarding the effect of linguistic variables on the temporal parameters of speech, Strand and McNeil (1996:103) stated "It may be reasonable to assume that different levels or processes of the speech production mechanism either interact in a direct way or share common underlying processing resources that could generate or contribute to errors". In this view, the influence of L2 on temporal control during speech production can be due to the simultaneous demands of L2 language formulation and motor control processes on processing resources. When the processing demands are increased with an increase in speaking rate and speaking in L2, both motor and linguistic levels of speech production compete for processing resources.

\section{CONCLUSIONS}


The results of the present study provide preliminary evidence that the language of production (L1 versus L2) can be viewed as a contextual factor which influences the complexity of speech production in speakers with neurogenic disorders and even in normal speakers. The current study did not differentiate between speakers with AOS and all speakers who display PP. It appears as if the increased processing demands imposed by speaking in L2 are manifested in the extent of durational adjustment in L2 versus L1 in most persons with AOS and some with PP. Individual differences appear to be present regarding the impact of these increased processing demands on various speakers, temporal parameters and utterance groups.

From the results of the present study, the need for further research regarding speech production in a second language becomes evident. Normal speakers should be studied in greater depth to establish a norm for the effect of L1 versus L2 on normal speech production. Further research could include, for example, the study of the speech of individual speakers over a wider range of behaviors, since not all normal and experimental participants appear to be affected in the same way by speech production in L2. An analysis of spatial parameters, together with temporal parameters of speech production, might be useful in highlighting the extent and nature of trade-offs during speech production in L1 and L2 respectively. A study of the effect of speech production in L1 versus L2 on the frequency and type of sound level errors using perceptual analysis could differentiate between speakers with AOS versus PP. The degree of the disorder should also be controlled. Linguistically more complex tasks may also differentiate between disorders on a phonological planning level and the speech motor planning and programming levels. 
In conclusion, the results of the present study suggest that more studies investigating the influence of speech production in L1 versus L2, on the speech of normal speakers and speakers with neurogenic communication disorders are necessary, using other parameters of speech production as well as different methods of analysis and speech material. Further research of this nature is imperative for a better understanding of bi- and multilingual speech and language processing, and speech and language disorders in these populations. 


\section{REFERENCES}

Abbeduto, L. (1985). The effects of linguistic complexity on children's and adults' motor programming of speech. Language and Speech, 28, 361-375.

Bock, J. K. (1982). Toward a cognitive psychology of syntax: Information processing contribution to sentence formulation. Psychological Review, 89, 1-47.

Caramazza, A., Yeni-Komshian, G., Zurif, E., \& Carbone, E. (1973). The acquisition of a new phonological contrast: The case of stop consonants in French-English bilinguals. Journal of the Acoustical Society of America, 54, 421-428.

Centeno, J. G. (2005). Working with bilingual individuals with aphasia: The case of a Spanish-English bilingual client. American Speech-Language-Hearing Association Division 14 - Perspectives on Communication Disorders and Sciences in Culturally and Linguistically Diverse Populations, 12, 2-7.

Clark, J., \& Robin, D. A. (1998). Generalized motor programme and parameterization accuracy in apraxia of speech and conduction aphasia. Aphasiology, 12, 699713.

Fossett, T. R. D., McNeil, M. R., \& Pratt, S. R. (2001). The effects of speaking rate manipulation on phonological encoding. Brain and Language, 79, 69-71.

Gil, M., \& Goral, M. (2004). Nonparallel recovery in bilingual aphasia: Effects of language choice, language proficiency, and treatment. International Journal of Bilingualism, 8, 191-219.

Guy, F. R., Edgley, C. E., Arafat, I., \& Allen, D. E. (1987). Social research methods: Puzzles and solutions. Boston: Allyn and Bacon. 
Haley, K.L., Ohde, R.N. \& Wertz, R.T. (2001). Vowel quality in aphasia and apraxia of speech: Phonetic transcription and formant analysis. Aphasiology, 15 (12), 11071123.

Jaric, S., Corcos, D. M., Argarwal, G. C., \& Gottlieb, G. L. (1993). Principles for learning single-joint movements, II: Generalizing a learned behavior. Experimental Brain Research, 94, 514-521.

Kay Elemetrics Corporation. (1994). Computerized Speech Lab (Version 5.X) [Computer software]. Lincoln Park: Kay Elemetrics Corporation.

Kelso, J. A. S., \& Tuller, B. (1981). Toward a theory of apractic syndromes. Brain and Language, 12, 224-245.

Kent, R. D. (1990). The acoustic and physiological characteristics of neurologically impaired speech movements. In W. J. Hardcastle, \& A. Marchal (Eds.), Speech Production and Speech Modelling (pp. 365-401). Netherlands: Kluwer Academic Publishers.

Kent, R. D., \& McNeil, M. R. (1987). Relative timing of sentence repetition in apraxia of speech and conduction aphasia. In J. H. Ryalls (Ed.), Phonetic approaches to speech production in aphasia and related disorders (pp. 181220). Boston: College-Hill Press.

Kent, R. D., \& Rosenbek, J. C. (1983). Acoustic patterns of apraxia of speech. Journal of Speech and Hearing Research, 26, 231-249.

Kent, R.D. \& Read, C. (2002). Acoustic analysis of speech. (2 ${ }^{\text {nd }}$ Edition). Albany: Singular Thomas Learning.

Kertesz, A. (1982). Western Aphasia Battery. New York: Grune \& Stratton. 
Kiran, S., \& Edmonds, L. A. (2004). Effect of semantic naming treatment on crosslinguistic generalization in bilingual aphasia. Brain and Language, 91, 7577.

Klein, D., Zatorre, R. J., Milner, B., Meyer, E., \& Evans, A. C. (1995). The neural substrates of bilingual language processing: Evidence from positron emission tomography. In M. Paradis (Ed.), Aspects of bilingual aphasia (pp. 23-36). Oxford: Elsevier Science.

Kohnert, K. (2004). Cognitive and cognate-based treatments for bilingual aphasia: A case study. Brain and Language, 91, 294-302.

Levelt, W. (1989). Speaking: From intention to articulation. Cambridge, MA: IT Press.

Lisker, L., \& Abramson, A. S. (1964). A cross language study of voicing in initial stops: Acoustical measurements. Word, 20, 384-422.

Lubker, J., \& Gay, T. (1981). Spatio-temporal goals: Maturational and cross-linguistic variables. In S. Grillner, B. Lindblom, J. Lubker, \& A. Persson (Eds.), Speech Motor Control (pp. 205-210). Oxford: Pergamon Press.

Magill, R. A. (2007). Motor Learning and Control: Concepts and Applications. Boston: McGraw-Hill Companies, Inc.

Maner, K. J., Smith, A., \& Grayson, L. (2000). Influences of utterance length and complexity on speech motor performance in children and adults. Journal of Speech and Hearing Research, 43, 560-573.

McNeil, M.R., Weismer, G., Adams, S. \& Mulligan, M. (1990). Oral structure nonspeech control in normal, dysarthric, aphasic, and apraxic speakers: Isometric force and static position control. Journal of Speech and Hearing Research, 33, 255-268. 
McNeil, M. R., Liss, J. M., Tseng, C., \& Kent, R. D. (1990). Effect of speech rate on the absolute and relative timing of apraxic and conduction aphasic sentence production. Brain and Language, 38, 135-158.

McNeil, M. R., Odell, K., \& Tseng, C. H. (1991). Toward the integration of resource allocation into a general theory of aphasia. Clinical Aphasiology, 20, 21-39.

McNeil, M.R., Robin, D.A., Schmidt R.A. (1997). Apraxia of speech. In M. R. McNeil (Ed.), Clinical management of sensorimotor speech disorders. New York: Thieme.

McNeil, M.R., Doyle, P.J. \& Wambaugh, J. (2000). Apraxia of speech: A treatable disorder of motor planning and programming. In S.E. Nadeau, L.J.G. Rothi, \& B. Crosson (Eds.) Aphasia and Language: Theory to Practice. New York: The Guilford Press.

McNeil, M.R., Pratt, S.R. \& Fossett, T.R.D. (2004). The differential diagnosis of apraxia of speech. In B. Maassen, R.D. Kent, H.F.M. Peters, P.H.H.M. van Lieshout, \& W. Hulstijn (Eds.) Speech Motor Control in Normal and Disordered Speech. New York: Oxford University press.

Ostry, D. J., \& Munhall, K. G. (1985). Control of rate and duration of speech movements. Journal of the Acoustical Society of America, 77, 640-648.

Paradis, M. (1995). Introduction: The need for distinctions. In M. Paradis (Ed.), Aspects of Bilingual Aphasia (pp. 1-9). United Kingdom: Elsevier Science Ltd.

Rogers, M. A., \& Storkel, H. L. (1999). Planning speech one syllable at a time: The reduced buffer capacity hypothesis in apraxia of speech. Aphasiology, 13, 793805.

Rosenbek, J. C. (2001). Darley and apraxia of speech in adults. Aphasiology, 15, 3, 261-273. 
Schmidt, R. A. (1988). Motor control and learning: A behavioral emphasis. Champaign, IL: Human Kinetics.

Seddoh, S., Robin, D. A., Sim, H. S., Hageman, C., Moon, J. B., \& Folkins, J. W. (1996). Speech timing in apraxia of speech versus conduction aphasia. Journal of Speech and Hearing Research, 39, 590-603.

Shriberg, L. D., \& Kent, R. D. (1982). Clinical Phonetics. New York: John Wiley \& Sons.

Smit, G. J. (1983). Navorsingsmetodes in die gedragswetenskappe. Pretoria: HAUM Opvoedkundige Uitgewers.

Smith, A. (1992). The control of orofacial movements in speech. Critical Reviews in Oral Biology and Medicine, 3, 3, 233-267.

Strand, E. A., \& McNeil, M. R. (1996). Effects of length and linguistic complexity on temporal acoustic measures in apraxia of speech. Journal of Speech and Hearing Research, 39, 1018-1033.

Theron, K. (2003). Temporal aspects of speech production in bilingual speakers with neurogenic speech disorders. Doctoral Dissertation, University of Pretoria [unpublished].

Van der Merwe, A., Uys, I.C., Loots J.M. \& Grimbeek, R.J. (1987). Die effek van sekere kontekstuele faktore op die perseptuele simptome van verbale apraksie (The influence of certain contextual factors on the perceptual symptoms of apraxia of speech). South African Journal of Communication Disorders, 34, 1022.

Van der Merwe, A. (1997). A theoretical framework for the characterization of pathologic speech sensorimotor control. In M. R. McNeil (Ed.), Clinical management of sensorimotor speech disorders (pp. 1-25). New York: Thieme. 
Van der Merwe, A., \& Tesner, H. (2000). Apraxia of speech in a bilingual speaker: Perceptual characteristics and generalization of non-language specific treatment. South African Journal of Communication Disorders, 47, 79-89.

Van der Merwe, A. (2002). The four-level framework for the characterization of pathological speech sensorimotor control: Applications to treating apraxia of speech. Keynote address presented at the $32^{\text {nd }}$ Annual Clinical Aphasiology Conference, Ridgedale, MO.

Van der Merwe, A. (2009). A theoretical framework for the characterization of pathologic speech sensorimotor control. In M. R. McNeil (Ed.), Clinical management of sensorimotor speech disorders. New York: Thieme.

Van der Merwe, A. (2007). Self-correction in apraxia of speech: The effect of treatment. Aphasiology, 21, 6/7/8, 658-669.

Whiteside, S. P., \& Varley, R. A. (1998). A reconceptualisation of apraxia of speech: A synthesis of evidence. Cortex, 34, 221-231. 
Table 1

Summary of biographical and descriptive data of the participants with apraxia of

speech or phonemic paraphasias

\begin{tabular}{|c|c|c|c|c|c|c|c|}
\hline & Participants & AOS1 & AOS2 & AOS3 & PP1 & PP2 & PP3 \\
\hline & Gender & $\mathrm{M}$ & $\mathrm{F}$ & $\mathrm{F}$ & $\mathrm{M}$ & $\mathrm{F}$ & $\mathrm{M}$ \\
\hline & Age (years) & 59 & 68 & 43 & 64 & 85 & 74 \\
\hline & $\begin{array}{l}\text { Time since } \\
\text { cerebrovascular } \\
\text { accident }\end{array}$ & 8years & 2 years & 3 years & 8 months & 2 years & 2 years \\
\hline \multirow{7}{*}{ 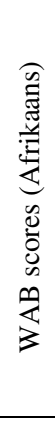 } & Fluency & $5 / 10$ & $9 / 10$ & $9 / 10$ & $6 / 10$ & $8 / 10$ & $9 / 10$ \\
\hline & Information & $9 / 10$ & $10 / 10$ & $10 / 10$ & $9 / 10$ & $7 / 10$ & $10 / 10$ \\
\hline & $\begin{array}{l}\text { Auditory } \\
\text { comprehension }\end{array}$ & $200 / 200$ & $200 / 200$ & $200 / 200$ & $161 / 200$ & $181 / 200$ & $189 / 200$ \\
\hline & Repetition & $82 / 100$ & $88 / 100$ & $92 / 100$ & $38 / 100$ & $91 / 100$ & $62 / 100$ \\
\hline & Naming & $90 / 100$ & $89 / 100$ & $88 / 100$ & $51 / 100$ & $75 / 100$ & $93 / 100$ \\
\hline & Aphasia Quotient & 82 & 93 & 94 & 64 & 81 & 88 \\
\hline & $\begin{array}{l}\text { Classification according } \\
\text { to the WAB (Kertesz, } \\
\text { 1982) }\end{array}$ & $\begin{array}{l}\text { Mild } \\
\text { anomic } \\
\text { aphasia }\end{array}$ & $\begin{array}{c}\text { mild } \\
\text { anomic } \\
\text { aphasia }\end{array}$ & $\begin{array}{l}\text { mild } \\
\text { anomic } \\
\text { aphasia }\end{array}$ & $\begin{array}{c}\text { mild } \\
\text { conduction } \\
\text { aphasia }\end{array}$ & $\begin{array}{l}\text { mild } \\
\text { anomic } \\
\text { aphasia }\end{array}$ & $\begin{array}{c}\text { mild } \\
\text { conduction } \\
\text { aphasia }\end{array}$ \\
\hline \multirow{7}{*}{ 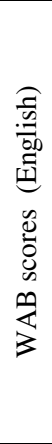 } & Fluency & $4 / 10$ & $9 / 10$ & $9 / 10$ & not tested & $8 / 10$ & $9 / 10$ \\
\hline & Information & $8 / 10$ & $10 / 10$ & $10 / 10$ & not tested & $7 / 10$ & $10 / 10$ \\
\hline & $\begin{array}{l}\text { Auditory } \\
\text { comprehension }\end{array}$ & $200 / 200$ & $197 / 200$ & $200 / 200$ & not tested & $178 / 200$ & $162 / 200$ \\
\hline & Repetition & $77 / 100$ & $74 / 100$ & $94 / 100$ & not tested & $91 / 100$ & $58 / 100$ \\
\hline & Naming & $58 / 100$ & $72 / 100$ & $87 / 100$ & not tested & $61 / 100$ & $73 / 100$ \\
\hline & Aphasia Quotient & 71 & 87 & 94 & not tested & 78 & 80 \\
\hline & $\begin{array}{l}\text { Classification according } \\
\text { to the WAB (Kertesz, } \\
\text { 1982) }\end{array}$ & $\begin{array}{l}\text { Mild } \\
\text { Broca's } \\
\text { aphasia }\end{array}$ & $\begin{array}{l}\text { mild } \\
\text { anomic } \\
\text { aphasia }\end{array}$ & $\begin{array}{l}\text { mild } \\
\text { anomic } \\
\text { aphasia }\end{array}$ & not tested & $\begin{array}{l}\text { moderate } \\
\text { anomic } \\
\text { aphasia }\end{array}$ & $\begin{array}{c}\text { mild } \\
\text { conduction } \\
\text { aphasia }\end{array}$ \\
\hline
\end{tabular}


Table 2

Speech stimuli

\begin{tabular}{|c|c|c|c|c|}
\hline & Utterance & Phonetic transcription & Language & Translated meaning \\
\hline \multirow{10}{*}{ 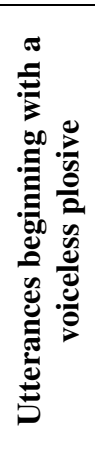 } & Dis 'n pet. & /dəsə pet// & Afrikaans & It's a cap. \\
\hline & It's a pet. & /Itsə pet/ & English & \\
\hline & Dis 'n pad. & /dəsə pat/ & Afrikaans & It's a road. \\
\hline & It's a putt. & /Itsə $\mathrm{p} \Lambda \mathrm{t} /$ & English & \\
\hline & Dis 'n pak. & /dəsə pak/ & Afrikaans & It's a suit/packet. \\
\hline & It's a puck. & /Itsə $\mathrm{p} \Lambda \mathrm{k} /$ & English & \\
\hline & Dis 'n pap. & /dəsə pap/ & Afrikaans & It's a porridge. \\
\hline & It's a pup. & /Itsə $\mathrm{p} \Lambda \mathrm{p} /$ & English & \\
\hline & Dis 'n pit. & /dəsə pət/ & Afrikaans & It's a pit. \\
\hline & It's a pit. & /Itsə pit/ & English & \\
\hline \multirow{10}{*}{ 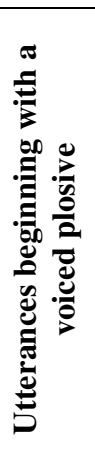 } & Dis 'n bak. & /dəsə bak/ & Afrikaans & It's a bowl. \\
\hline & It's a buck. & /Itsə bムk/ & English & \\
\hline & Dis 'n bas. & /dəsə bas/ & Afrikaans & It's a bark. \\
\hline & It's a bus. & /Itsə b $\Lambda \mathrm{s} /$ & English & \\
\hline & Dis 'n bed. & /dəsə bet/ & Afrikaans & It's a bed. \\
\hline & It's a bet. & /Itsə bet/ & English & \\
\hline & Dis 'n byt. & /dəsə bəit/ & Afrikaans & It's a bite. \\
\hline & It's a bait. & /Itsa bəIt/ & English & \\
\hline & Dis 'n bek. & /dəsə bæk/ & Afrikaans & It's a mouth. \\
\hline & It's a back. & /Itsə bæk/ & English & \\
\hline
\end{tabular}


Table 3

Summarized findings for each participant and the normal speakers regarding durational adjustments for each temporal parameter and utterance group

\begin{tabular}{|c|c|c|c|c|c|c|c|c|c|c|c|c|}
\hline \multicolumn{13}{|c|}{ Vowel duration } \\
\hline Finding & AOS1 & AOS2 & AOS3 & N1 & $\mathbf{N 2}$ & N3 & N4 & N5 & $\begin{array}{l}\text { Normal } \\
\text { speakers } \\
\text { as a } \\
\text { Group } \\
\text { (NGR) }\end{array}$ & PP1 & PP2 & PP3 \\
\hline \multicolumn{13}{|c|}{ Voiceless Plosives } \\
\hline $\mathrm{A}$ & NA & & $\mathrm{X}$ & & & & & & & & NA & NA \\
\hline $\mathrm{B}$ & NA & $\mathrm{X}$ & $\mathrm{X}$ & & & & & $\mathrm{X}$ & & & NA & NA \\
\hline $\mathrm{C}$ & NA & & & & & $\sqrt{ }$ & & & & & & \\
\hline $\mathrm{D}$ & NA & & & $\sqrt{ }$ & $\sqrt{ }$ & $\sqrt{ }$ & $\sqrt{ }$ & & $\sqrt{ }$ & $\sqrt{ }$ & & \\
\hline \multicolumn{13}{|c|}{ Voiced Plosives } \\
\hline $\mathrm{A}$ & NA & & & & & & & & & & $\mathrm{X}$ & $\mathrm{X}$ \\
\hline $\mathrm{B}$ & NA & $\mathrm{X}$ & $\mathrm{X}$ & & $\mathrm{X}$ & & & $\mathrm{X}$ & & & $\mathrm{X}$ & $\mathrm{X}$ \\
\hline $\mathrm{C}$ & NA & & & & & & & & & & & \\
\hline $\mathrm{D}$ & NA & & & $\sqrt{ }$ & & $\sqrt{ }$ & $\sqrt{ }$ & & $\sqrt{ }$ & $\sqrt{ }$ & & \\
\hline \multicolumn{13}{|c|}{ Utterance duration } \\
\hline \multicolumn{13}{|c|}{ Voiceless Plosives } \\
\hline $\mathrm{A}$ & & & & & & & & & & & $X$ & \\
\hline $\mathrm{B}$ & $\mathrm{X}$ & $\mathrm{X}$ & $\mathrm{X}$ & & & & & $\mathrm{X}$ & & $\mathrm{X}$ & $\mathrm{X}$ & $\mathrm{X}$ \\
\hline $\mathrm{C}$ & & & & & & & & & & & & \\
\hline $\mathrm{D}$ & & & & $\sqrt{ }$ & $\sqrt{ }$ & $\sqrt{ }$ & $\sqrt{ }$ & & $\sqrt{ }$ & & & \\
\hline \multicolumn{13}{|c|}{ Voiced Plosives } \\
\hline A & & & & & & & & & & & $\mathrm{X}$ & \\
\hline $\mathrm{B}$ & & $\mathrm{X}$ & $\mathrm{X}$ & & $\mathrm{X}$ & & & $\mathrm{X}$ & & $\mathrm{X}$ & $\mathrm{X}$ & \\
\hline $\mathrm{C}$ & & & & & & & & & & & & \\
\hline $\mathrm{D}$ & $\sqrt{ }$ & & & $\sqrt{ }$ & & $\sqrt{ }$ & $\sqrt{ }$ & & $\sqrt{ }$ & & & $\sqrt{ }$ \\
\hline \multicolumn{13}{|c|}{ Utterance onset duration } \\
\hline \multicolumn{13}{|c|}{ Voiceless Plosives } \\
\hline A & NA & $\mathrm{X}$ & & & & & & & & & $\mathrm{X}$ & $\mathrm{X}$ \\
\hline $\mathrm{B}$ & NA & $\mathrm{X}$ & $\mathrm{X}$ & & $\mathrm{X}$ & $\mathrm{X}$ & $\mathrm{X}$ & $\mathrm{X}$ & $\mathrm{X}$ & $\mathrm{X}$ & $\mathrm{X}$ & $\mathrm{X}$ \\
\hline $\mathrm{C}$ & NA & & & & & & & & & & & \\
\hline $\mathrm{D}$ & NA & & & $\sqrt{ }$ & & & & & & & & \\
\hline \multicolumn{13}{|c|}{ Voiced Plosives } \\
\hline A & & & $\mathrm{X}$ & & & & & & & & & $\mathrm{X}$ \\
\hline $\mathrm{B}$ & $\mathrm{X}$ & & $\mathrm{X}$ & & $\mathrm{X}$ & $\mathrm{X}$ & & $\mathrm{X}$ & & & $\mathrm{X}$ & $\mathrm{X}$ \\
\hline $\mathrm{C}$ & & & & & & & & & & & & \\
\hline $\mathrm{D}$ & & $\sqrt{ }$ & & $\sqrt{ }$ & & & $\sqrt{ }$ & & $\sqrt{ }$ & $\sqrt{ }$ & & \\
\hline \multicolumn{13}{|c|}{ Voice onset time } \\
\hline \multicolumn{13}{|c|}{ Voiceless Plosives } \\
\hline $\mathrm{A}$ & & & & & & & & & & & $\mathrm{X}$ & \\
\hline $\mathrm{B}$ & & & & & & & $\mathrm{X}$ & & & & $\mathrm{X}$ & $X$ \\
\hline $\mathrm{C}$ & $\sqrt{ }$ & & & & $\sqrt{ }$ & $\sqrt{ }$ & & & & & & \\
\hline $\mathrm{D}$ & $\sqrt{ }$ & $\sqrt{ }$ & $\sqrt{ }$ & $\sqrt{ }$ & $\sqrt{ }$ & $\sqrt{ }$ & & $\sqrt{ }$ & $\sqrt{ }$ & $\sqrt{ }$ & & \\
\hline
\end{tabular}

$\mathrm{A}=$ Duration in the FR could be decreased in L1 only

$\mathrm{B}=$ The extent/percentage of durational adjustment was greater in L1 than in L2

$\mathrm{C}=$ Duration in the FR could be decreased in L2 only

$\mathrm{D}=$ The extent/percentage of durational adjustment was greater in L2 than in L1

$\mathrm{NA}=$ Not applicable. Comments regarding the extent of durational adjustment cannot be made since duration in the FR could not be decreased in either language. 
Table 4

Mean duration of each parameter in the fast rate (FR) expressed as a percentage of the duration in the normal rate (NR) for each utterance group

in L1 and L2 respectively. A value $>0$ indicates that duration was successfully decreased in the fast rate whilst a value $<0$ indicates that duration in the FR was longer than duration in the NR.

\begin{tabular}{|c|c|c|c|c|c|c|c|c|c|c|c|c|c|c|}
\hline & \multirow{2}{*}{\multicolumn{2}{|c|}{\begin{tabular}{|c}
$\begin{array}{c}\text { Vowel duration } \\
\text { Voiceless } \\
\text { plosive }\end{array}$ \\
utterance group \\
$\begin{array}{c}\text { Percentage of } \\
\text { durational }\end{array}$ \\
adjustment in FR
\end{tabular}}} & \multicolumn{2}{|c|}{$\begin{array}{l}\text { Vowel duration } \\
\text { Voiced plosive } \\
\text { utterance group }\end{array}$} & \multicolumn{2}{|c|}{$\begin{array}{c}\text { Utterance } \\
\text { duration } \\
\text { Voiceless } \\
\text { plosive } \\
\text { utterance group }\end{array}$} & \multicolumn{2}{|c|}{$\begin{array}{c}\text { Utterance } \\
\text { duration } \\
\text { Voiced plosive } \\
\text { utterance } \\
\text { group }\end{array}$} & \multicolumn{2}{|c|}{$\begin{array}{c}\text { Utterance onset } \\
\text { duration } \\
\text { Voiceless plosive } \\
\text { utterance group }\end{array}$} & \multicolumn{2}{|c|}{$\begin{array}{c}\text { Utterance onset } \\
\text { duration } \\
\text { Voiced plosive } \\
\text { utterance group }\end{array}$} & \multicolumn{2}{|c|}{$\begin{array}{l}\text { Voice onset time } \\
\text { Voiceless plosive } \\
\text { utterance group }\end{array}$} \\
\hline & & & $\begin{array}{r}\text { Perce } \\
\text { dur } \\
\text { adjustn }\end{array}$ & $\begin{array}{l}\text { se of } \\
\text { nal } \\
\text { in FR }\end{array}$ & $\begin{array}{r}\text { Perce } \\
\text { dur } \\
\text { adjustr }\end{array}$ & $\begin{array}{l}\text { ge of } \\
\text { nal } \\
\text { in FR }\end{array}$ & $\begin{array}{r}\text { Perce } \\
\text { dur: } \\
\text { adjustm }\end{array}$ & $\begin{array}{l}\text { ge of } \\
\text { nal } \\
\text { in FR }\end{array}$ & $\begin{array}{r}\text { Percen } \\
\text { dura } \\
\text { adjustme }\end{array}$ & $\begin{array}{l}\text { e of } \\
\text { al } \\
\text { in FR } \\
\text { in }\end{array}$ & $\begin{array}{r}\text { Perc } \\
\text { dur } \\
\text { adjust }\end{array}$ & $\begin{array}{l}\text { se of } \\
\text { nal } \\
\text { in FR }\end{array}$ & $\begin{array}{r}\text { Per } \\
\text { du } \\
\text { adjus }\end{array}$ & $\begin{array}{l}\text { ge of } \\
\text { nal } \\
t \text { in FR }\end{array}$ \\
\hline & L1 & L2 & L1 & L2 & L1 & L2 & L1 & L2 & L1 & $\mathbf{L 2}$ & L1 & L2 & L1 & L2 \\
\hline AOS1 & -15.8 & -5.3 & -7.2 & -1.1 & 8.2 & 5.9 & 11.4 & 12.1 & -47.3 & -11.0 & 28.9 & 23.6 & -7.9 & 1.5 \\
\hline AOS2 & 2.6 & 0.8 & 8.4 & 4.0 & 29.0 & 17.1 & 31.6 & 14.7 & 31.1 & -52.0 & 9.4 & 20.9 & 1.5 & 6.4 \\
\hline AOS3 & 15.9 & -0.6 & 17.7 & 10.5 & 10.7 & 8.6 & 17.6 & 10.6 & 36.2 & 4.7 & 29.4 & -39.9 & 9.3 & 32.2 \\
\hline N1 & 9.9 & 21.4 & 7.2 & 21.4 & 20.7 & 28.8 & 21.7 & 28.1 & 44.7 & 53.5 & 46.9 & 63.2 & 13.6 & 32.9 \\
\hline N2 & 7.8 & 13.5 & 18.4 & 15.3 & 11.4 & 16.7 & 16.4 & 7.8 & 41.6 & 32.4 & 46.4 & 38.1 & -2.0 & 2.2 \\
\hline N3 & -3.1 & 9.4 & 9.8 & 16.4 & 8.8 & 14.3 & 14.7 & 19.1 & 33.0 & 26.8 & 37.8 & 26.8 & -2.1 & 3.2 \\
\hline N4 & 9.6 & 11.2 & 11.1 & 12.6 & 16.4 & 20.2 & 18.6 & 27.3 & 24.1 & 16.7 & 13.9 & 17.2 & 9.2 & 3.1 \\
\hline N5 & 17.5 & 1.1 & 13.7 & 3.2 & 27.8 & 18.6 & 23.1 & 14.8 & 20.4 & 10.7 & 23.1 & 4.4 & 7.8 & 16.5 \\
\hline NGR & 8.5 & 11.7 & 12.4 & 14.2 & 17.1 & 19.9 & 19.1 & 19.9 & 33.4 & 29.6 & 34.7 & 34.8 & 5.4 & 11.7 \\
\hline PP1 & 5.6 & 14.5 & 12.6 & 16.9 & 13.3 & 9.8 & 20.0 & 12.6 & 61.5 & 50.7 & 24.4 & 43.2 & 9.1 & 24.9 \\
\hline PP2 & -4.1 & -4.4 & 3.2 & -7.1 & 11.6 & -4.5 & 6.8 & -2.7 & 20.7 & -21.3 & 12.4 & 4.1 & 21.6 & -33.4 \\
\hline PP3 & -7.1 & -10.2 & 4.6 & -1.9 & 1.9 & 1.4 & 6.5 & 9.5 & 33.8 & -25.7 & 27.5 & -28.2 & 2.9 & 2.4 \\
\hline
\end{tabular}




\section{Table 5}

Percentage of instances across dependent variables and utterance groups in which scenarios A to D were displayed for each participant and the normal speakers

\begin{tabular}{|c|c|c|c|c|c|c|c|c|c|c|c|c|}
\hline Scenario & AOS1 & AOS2 & AOS3 & N1 & N2 & N3 & N4 & N5 & $\begin{array}{l}\text { Normal } \\
\text { speakers } \\
\text { as a } \\
\text { Group } \\
\text { (NGR) }\end{array}$ & PP1 & PP2 & PP3 \\
\hline & $\%$ & $\%$ & $\%$ & $\%$ & $\%$ & $\%$ & $\%$ & $\%$ & $\%$ & $\%$ & $\%$ & $\%$ \\
\hline A & 0 & 14 & 29 & 0 & 0 & 0 & 0 & 0 & 0 & 0 & 71 & 43 \\
\hline B & 29 & 71 & 86 & 0 & 57 & 29 & 29 & 86 & 14 & 43 & 86 & 71 \\
\hline C & 14 & 0 & 0 & 0 & 14 & 29 & 0 & 0 & 0 & 0 & 0 & 0 \\
\hline D & 29 & 29 & 14 & 100 & 43 & 71 & 71 & 14 & 86 & 57 & 0 & 14 \\
\hline E & 43 & 0 & 0 & 0 & 0 & 0 & 0 & 0 & 0 & 0 & 14 & 14 \\
\hline
\end{tabular}

$\mathrm{A}=$ Duration in the FR could be decreased in L1 only

$\mathrm{B}=$ The extent/percentage of durational adjustment was greater in L1 than in L2 $\mathrm{C}=$ Duration in the FR could be decreased in L2 only

$\mathrm{D}=$ The extent/percentage of durational adjustment was greater in L2 than in L1

$\mathrm{E}=$ Duration in the FR could not be decreased in either language 


\section{Figure Captions}

Figure 1. A spectrograph of "Dis 'n pet" (English counterpart: "It's a pet") produced in L1NR by $\mathrm{N} 5$, indicating the four temporal parameters measured for utterances beginning with a voiceless plosive, namely utterance onset duration (UOD), voice onset time (VOT), vowel duration (VD) and utterance duration (UD).

Figure 2. VD in FR expressed as a percentage of VD in NR indicating the extent of durational adjustment in the FR compared to the NR in L1 and L2 for utterances beginning with a voiceless plosive.

Figure 3. VD in the FR expressed as a percentage of VD in the NR indicating the extent of durational adjustment in the FR compared to the NR in L1 and L2 for utterances beginning with a voiced plosive.

Figure 4. UD in FR expressed as a percentage of UD in NR indicating the extent of durational adjustment in the FR compared to the NR in L1 and L2 for utterances beginning with a voiceless plosive.

Figure 5. UD in FR expressed as a percentage of UD in NR indicating the extent of durational adjustment in the FR compared to the NR in L1 and L2 for utterances beginning with a voiced plosive.

Figure 6. UOD in FR expressed as a percentage of UOD in NR indicating the extent of durational adjustment in the FR compared to the NR in L1 and L2 for utterances beginning with a voiceless plosive.

Figure 7. UOD in FR expressed as a percentage of UOD in NR indicating the extent of durational adjustment in the FR compared to the NR in L1 and L2 for utterances beginning with a voiced plosive. 
Temporal parameters in bilinguals 48

Figure 8. VOT in FR expressed as a percentage of VOT in NR indicating the extent of durational adjustment in the FR compared to the NR in L1 and L2 for utterances beginning with a voiceless plosive. 


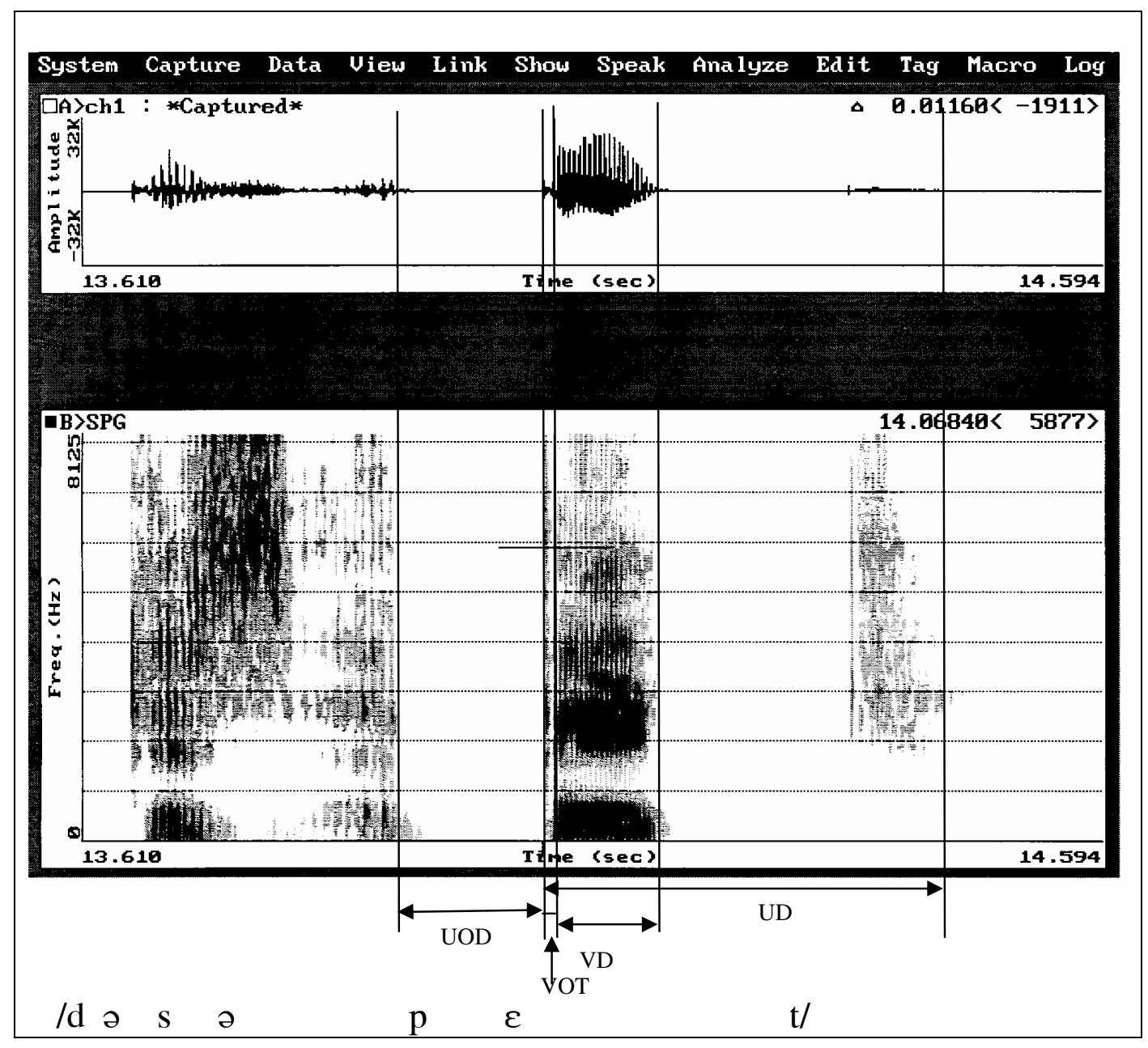




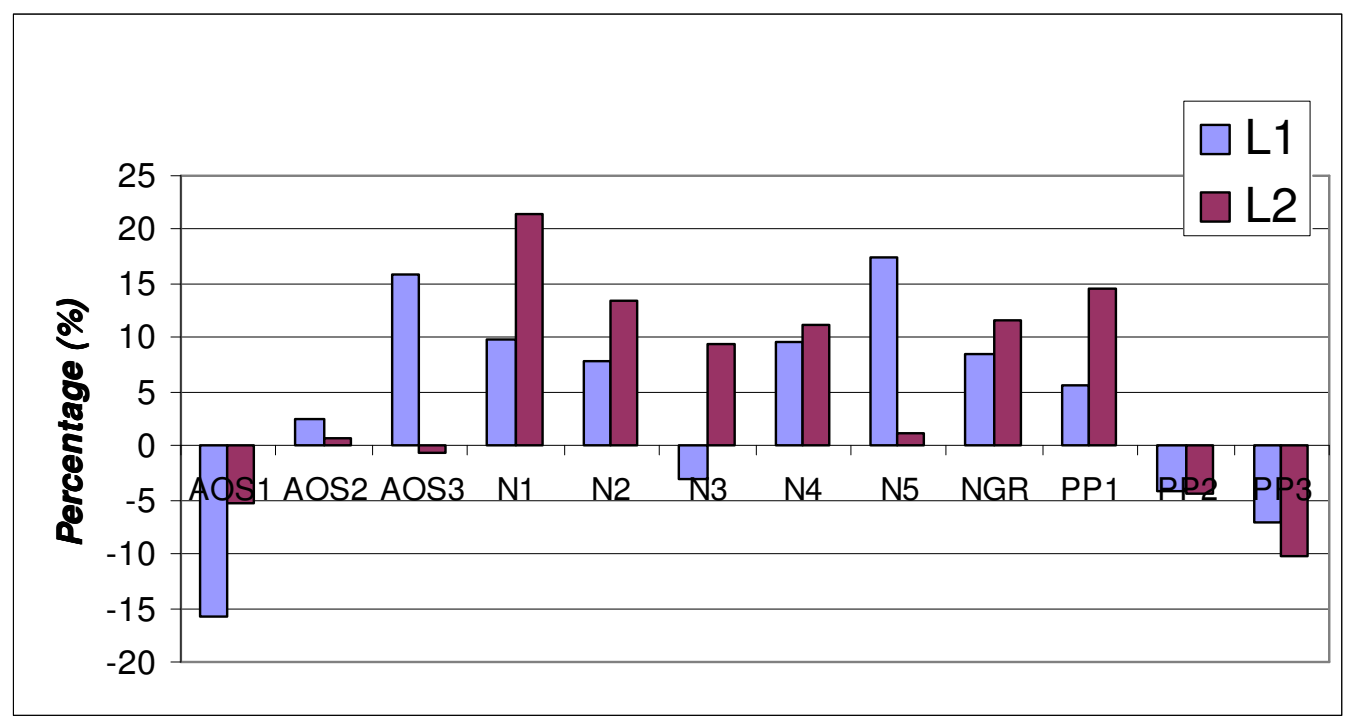


Temporal parameters in bilinguals 51

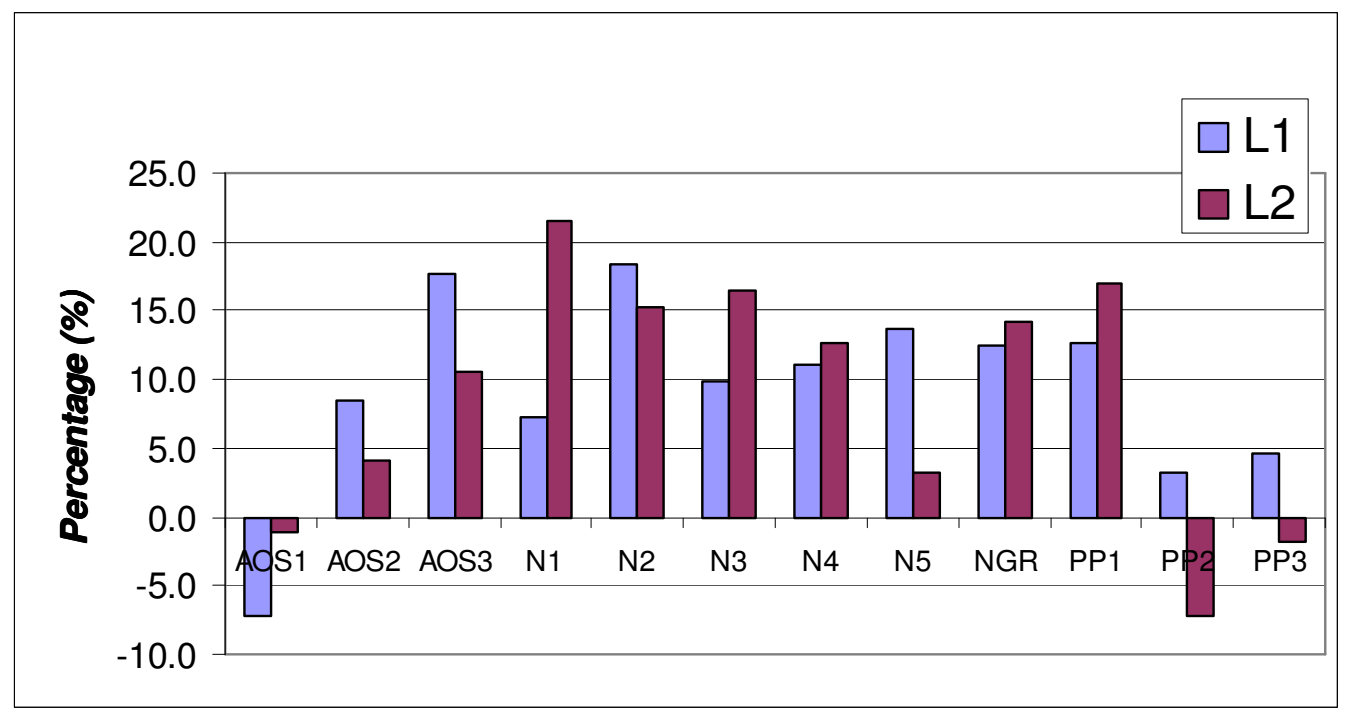


Temporal parameters in bilinguals 52

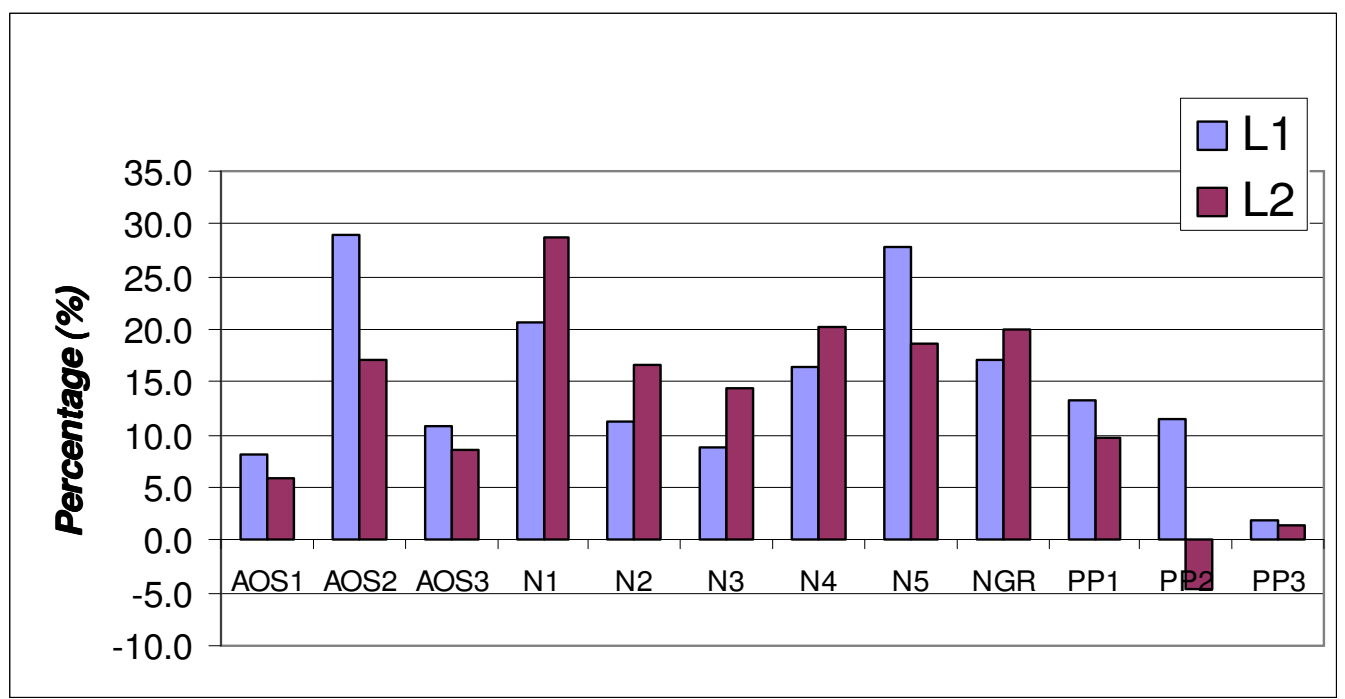


Temporal parameters in bilinguals 53

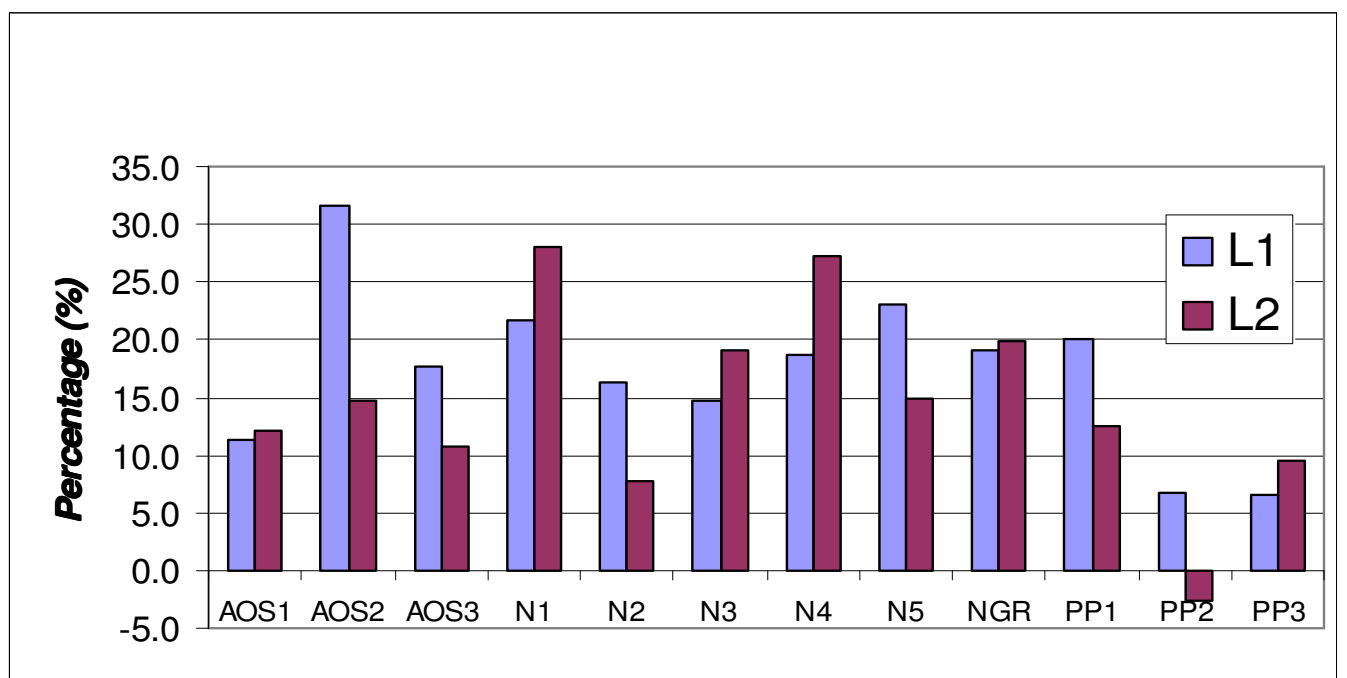


Temporal parameters in bilinguals 54

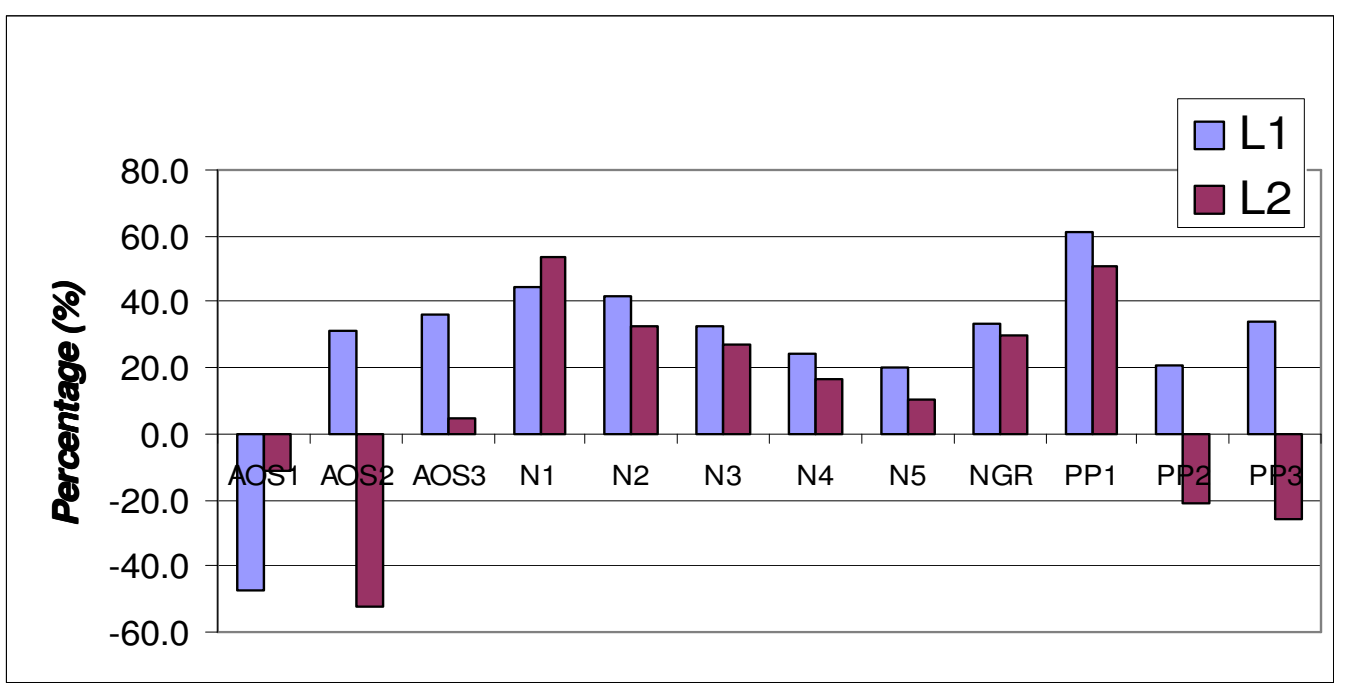


Temporal parameters in bilinguals 55

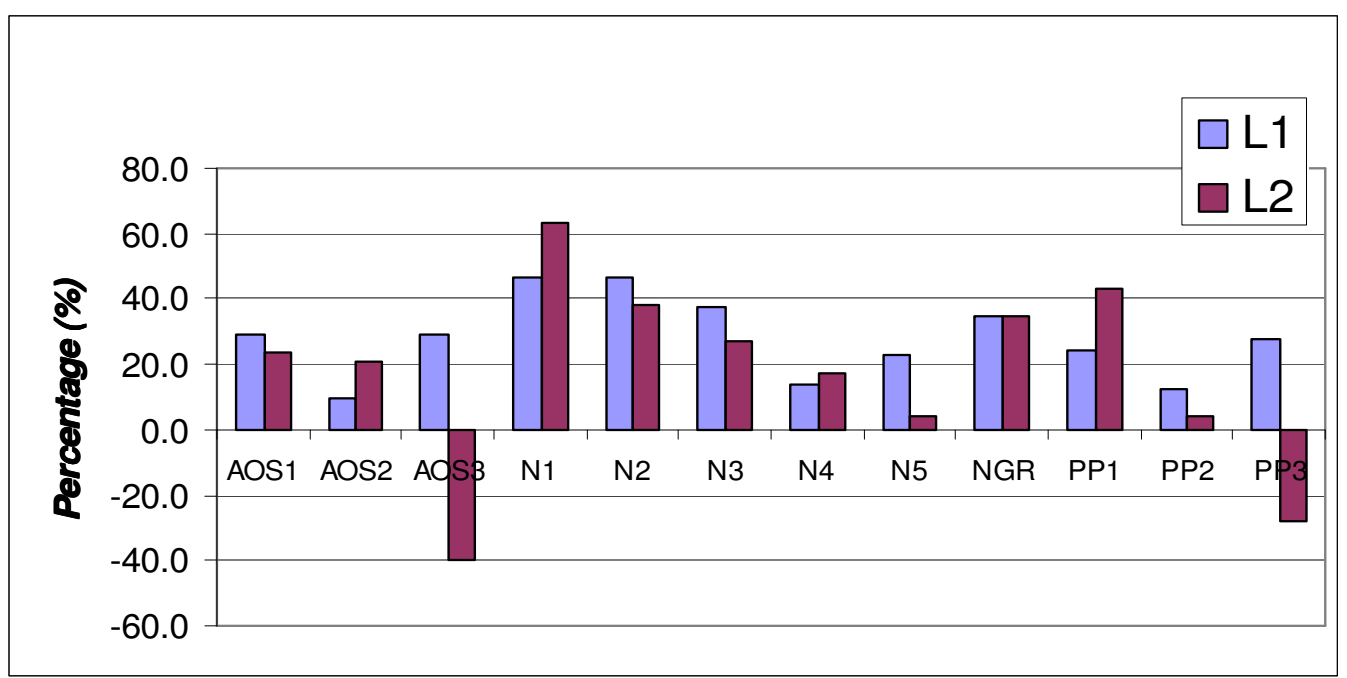


Temporal parameters in bilinguals 56

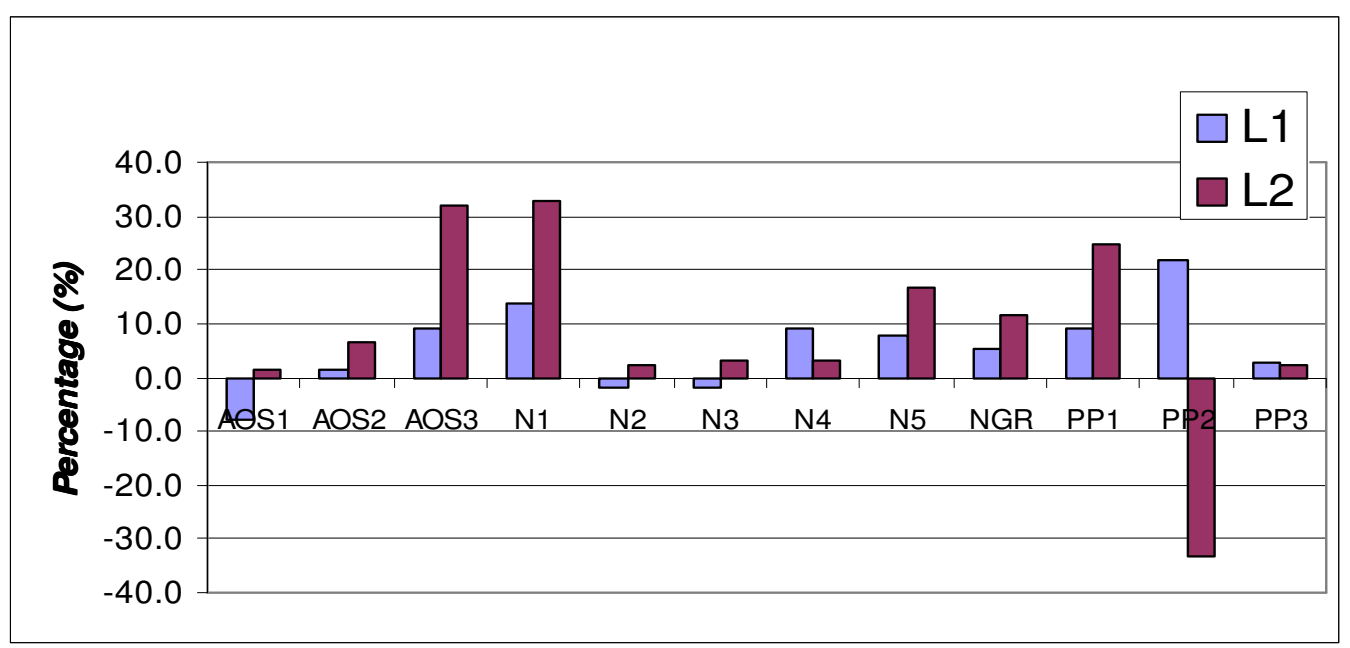

